\title{
Um estudo de caso explanatório sobre o desenvolvimento de atividades experimentais com enfoque no processo de modelagem científica para o ensino de Física
}

Leonardo Albuquerque Heidemann leonardo.h@ufrgs.br 0000-0001-5143-6275 Universidade Federal do Rio Grande do Sul - Brasil

Ives Solano Araujo ives@if.ufrgs.br 0000-0002-3729-0895 Universidade Federal do Rio Grande do Sul - Brasil

Eliane Angela Veit eav@if.ufrgs.br 0000-0002-2406-3415

Universidade Federal do Rio Grande do Sul - Brasil

\section{RESUMO}

Atividades experimentais realizadas nos cursos superiores de Física frequentemente incentivam os estudantes a agir de forma mecânica, sem refletir sobre os fundamentos teóricos que amparam suas investigações. Desse modo, contribuem para o desenvolvimento de um ensino dicotomizado, em que aspectos teóricos e experimentais são tratados de forma dissociada. Motivada por esse cenário, esta investigação, dando continuidade a um estudo exploratório previamente realizado, tem por objetivo avaliar atividades experimentais delineadas com o intuito de associar teoria e prática no ensino de Física por meio do enfoque no processo de modelagem científica. Para amparar tanto o delineamento das atividades, que tratavam de oscilações mecânicas, fluidos e termodinâmica, como a análise de seus resultados, foi utilizado como referencial teóricometodológico a Modelagem Didático-Científica de Brandão, Araujo e Veit. Foi avaliada a influência das atividades realizadas: nas atitudes dos estudantes frente às atividades experimentais; nas suas concepções sobre conceitos relacionados com o processo de modelagem científica; e nos seus avanços e dificuldades para enfrentar situações relacionadas com a construção, o uso e a validação de modelos didáticos-científicos. Os resultados sugerem que: i) a liberdade que os estudantes dispunham para delinear e conduzir seus experimentos foi um fator determinante para que eles construíssem atitudes favoráveis ou desfavoráveis às atividades experimentais realizadas, ii) os estudantes permaneceram com concepções confusas sobre os conceitos de modelo, teoria e modelagem e iii) foi bastante tímido o avanço dos participantes em suas capacidades para enfrentar as situações propostas.

PALAVRAS-CHAVE: atividades experimentais. modelagem científica. modelagem didáticocientífica. 


\section{INTRODUÇÃO}

A forma como atividades experimentais são frequentemente estruturadas no ensino de Ciências é profundamente criticada por pesquisadores desde muito tempo (Hodson, 1994; Trumper, 2003). O uso de roteiros excessivamente dirigidos tem levado os estudantes a realizar as tarefas de forma mecânica, sem refletir suficientemente sobre fundamentos teóricos que sustentam suas investigações. Além disso, é comum que as atividades sejam apoiadas implicitamente na concepção epistemológica ingênua de que as leis científicas são descobertas a partir da generalização de um conjunto de observações experimentais. Frente a esse cenário, investigamos neste artigo uma proposta de atividade experimental delineada com o objetivo de promover uma postura ativa dos estudantes no planejamento, execução e análise dos dados de experimentos, relacionando teoria e prática em suas investigações. Espera-se com isso dar-lhes oportunidade para que evoluam em suas concepções epistemológicas por meio da compreensão do papel dos modelos didáticos-científicos no processo de representação de eventos reais.

Em estudo exploratório previamente realizado (Heidemann, 2015; Heidemann, Araujo \& Veit, 2015a), investigamos a influência de atividades experimentais com enfoque no processo de modelagem científica envolvendo oscilações mecânicas, fluidos e termodinâmica em uma disciplina de Física Geral Experimental voltada para alunos da graduação em Física. Nesse estudo, procuramos avaliar: i) as atitudes de estudantes de em relação às aulas de laboratório; ii) na percepção deles sobre o que constitui uma boa aula de laboratório; e iii) na capacidade deles para relacionar os modelos teóricos da Física, o processo de modelagem científica e a experimentação. Os resultados evidenciaram que o enfoque no processo de modelagem científica gerou atitudes positivas em relação às aulas experimentais, especialmente em decorrência da liberdade que possuíam nas atividades. No entanto, possivelmente devido à forma implícita como aspectos epistemológicos foram tratados, não foi observada evolução satisfatória na capacidade dos estudantes de relacionar suas investigações com o processo de modelagem científica, e foi bastante tímido o avanço em suas concepções sobre a natureza da Ciência.

Tais resultados tornaram latente a necessidade de realização de um novo estudo em que fossem promovidas mudanças tanto na estrutura das atividades conduzidas, focando-as em debates e objetivos de aprendizagem explícitos relacionados com o processo de modelagem científica, como na análise dos seus resultados, voltando-a para uma avaliação do domínio dos estudantes sobre o campo conceitual da modelagem didático-científica (Brandão, Araujo e Veit, 2011; 2012). Procurando contemplar essa necessidade, foi realizada a pesquisa relatada neste artigo. Após uma fase exploratória da investigação, em que levantamos proposições pertinentes para serem avaliadas em estudos posteriores (Heidemann, Araujo e Veit, 2015a), realizamos este estudo explanatório em que estreitamos a abrangência da pesquisa e investimos em maior profundidade. 
O uso da Modelagem Didático-Científica (idem) como referencial teóricometodológico levou-nos a adotar a concepção de que a modelagem científica pode ser entendida como um campo conceitual subjacente aos campos conceituais da Física. Em decorrência, direcionamos nossa análise para a avaliação de aspectos relacionados com o enfrentamento, por parte dos estudantes, de situações do campo conceitual da modelagem didático-científica. Além disso, procuramos também aprofundar a investigação sobre a influência do enfoque no processo de modelagem científica sobre as atitudes dos estudantes frente às atividades experimentais. Precisamente, as questões de pesquisa deste estudo foram as seguintes:

Como e por que atividades experimentais focadas no processo de modelagem científica influenciam:

i) as crenças e atitudes dos estudantes em relação às atividades experimentais?

ii) o domínio do campo conceitual da modelagem didático-científica por parte dos estudantes?

Utilizamos aqui o termo "crença" para designar os conhecimentos dos estudantes que moldam suas atitudes. Por sua vez, "atitudes" são entendidas como disposições que refletem o sentimento dos estudantes para responder favorável ou desfavoravelmente frente a um objeto, pessoa, instituição ou evento (Heidemann, Araujo e Veit, 2012a).

Seguindo as orientação de Yin (2005), construímos, para cada uma dessas questões de pesquisa, proposições teóricas a serem avaliadas empiricamente por meio de múltiplos instrumentos de coleta de dados. Nas próximas seções, apresentaremos o referencial teórico-metodológico deste estudo, denominado Modelagem Didático-Científica, a metodologia de ensino e de pesquisa empregada, assim como os resultados obtidos na investigação.

\section{REFERENCIAL TEÓRICO-METODOLÓGICO: A MODELAGEM DIDÁTICO-CIENTÍFICA}

Proposta por Brandão, Araujo e Veit (2011; 2012), a Modelagem DidáticoCientífica é um referencial teórico-metodológico instituído a partir da compreensão de que existe um campo conceitual, na acepção de Vergnaud (1996), associado à construção, ao uso e à validação de versões didáticas de modelos científicos da Física, denominado de campo conceitual da modelagem didático-científica. Para elucidar os conhecimentos que podem amparar os esquemas de ação que os estudantes mobilizam quando enfrentam situações desse campo conceitual, os autores se amparam na Teoria dos Campos Conceituais de Vergnaud $(1996 ; 2009)$ e na concepção de modelagem científica de Bunge (1974) para identificar invariantes operatórios de referência (conceitos e teoremas) relacionados com o processo de modelagem científica.

Os conceitos de modelo teórico, de objeto-modelo e de teoria geral são exemplos de conceitos de referência do campo conceitual da modelagem didático-científica. Esses conceitos foram identificados por Brandão, Araujo e Veit (2011; 2012) adotando as concepções de Bunge (1974), que entende que um modelo teórico é uma representação simplificada da realidade construída com base em um objeto-modelo e em teorias gerais. 
Além de identificar onze conceitos de referência para o campo conceitual da modelagem didático-científica, Brandão, Araujo e Veit $(2011 ; 2012)$ constroem uma estrutura conceitual de referência em que destacam os vínculos mais importantes entre os conceitos identificados. Os autores usam o termo "estrutura conceitual de referência" na acepção de Otero (2006, p.27), que o cunhou para definir "o conjunto dos conceitos, das relações entre eles, dos princípios, das asserções de conhecimento e das explicações relativas a um campo conceitual, como ele é formulado, debatido e acordado nas discussões e nos textos especializados próprios de uma determinada comunidade científica de referência". Desse modo, na estrutura conceitual de referência do campo conceitual da modelagem didático-científica, por exemplo, os conceitos de objeto-modelo e de idealização são conectados, pois os objetos-modelo resultam das idealizações consideradas durante o processo de representação dos eventos reais.

Complementando os conhecimentos de referência que podem fundamentar as estruturas de pensamento mobilizadas pelos estudantes em situações de modelagem, Brandão, Araujo e Veit (idem) estabelecem um conjunto de treze teoremas que, conjuntamente com os conceitos identificados pelos autores, constituem os principais invariantes operatórios de referência do campo conceitual da modelagem didático-científica. Desses teoremas, quatro são de caráter geral, associados aos conceitos de modelo e modelagem, e nove são de caráter específico, vinculados a conceitos da estrutura conceitual de referência. Por exemplo, associado ao conceito de idealização, Brandão, Araujo e Veit (2011, p. 529) propõem o seguinte teorema: "Dado um sistema físico, decidir quais dos seus traços-chave apreender". Também propõem teoremas vinculados aos conceitos de referente, aproximação, variável, parâmetro, domínio de validade, grau de precisão, expansão e generalização.

A mais importante implicação didática da Modelagem Didático-Científica está nas características das atividades propostas aos estudantes nas aulas de Física. Em acordo com as ideias de Hodson (1994) e de Justi e Gilbert (2002), Brandão, Araujo e Veit $(2011 ; 2012)$ defendem que o ensino de Física precisa promover situações que possibilitem que os estudantes conheçam a natureza, o alcance e as limitações dos principais modelos produzidos pela Ciência, assim como compreendam o papel dos modelos no processo de validação e exploração dos produtos das investigações científicas. Além disso, os autores argumentam que os estudantes precisam ser defrontados com situações que demandem a criação e o teste de modelos.

Nesta investigação a Modelagem Didático-Científica norteou tanto o delineamento das atividades de ensino, conduzidas com foco em debates e objetivos de aprendizagem explícitos voltados para o desenvolvimento de conhecimentos do campo conceitual da modelagem didático-científica, como a análise dos dados coletados, em que buscamos avaliar o domínio desse campo conceitual por parte dos estudantes. Na próxima seção, detalharemos a metodologia de ensino adotada, esclarecendo como o enfoque no processo de modelagem científica foi implementado nas atividades experimentais propostas, e quais os seus objetivos de aprendizagem. 
As atividades com enfoque no processo de modelagem científica conduzidas neste estudo, que denominamos de atividades de modelagem, foram inspiradas nos ciclos de modelagem de Hestenes (2006). Elas foram conduzidas em três etapas:

i) discussão inicial: uma situação física era apresentada aos estudantes, juntamente com diversas questões sobre ela. Era solicitado, então, que em horário extraclasse, os alunos começassem a pensar em questões e montagens experimentais que possibilitassem uma investigação sobre a situação física proposta. Como não seria fornecido um roteiro para a investigação a ser realizada na fase seguinte, os estudantes deveriam consultar, e ter disponível na etapa de investigação, livros, revistas e/ou a internet;

ii) investigação: os alunos, organizados em pequenos grupos, definiam as suas questões de investigação, planejavam um delineamento experimental e sua execução, com liberdade para escolher os métodos de coleta e análise de dados utilizados. Sobre a bancada do laboratório, ficavam dispostos diversos objetos e instrumentos, cabendo a eles escolher os instrumentos de medida e os aparatos experimentais necessários. Também poderiam optar por usar outros objetos e instrumentos desde que os providenciassem com recursos caseiros ou de outros laboratórios da instituição. Pequenos quadros brancos $(90 \mathrm{~cm} \mathrm{X} 60 \mathrm{~cm})$ eram utilizados pelos estudantes para compartilharem suas ideias durante as investigações;

iii) discussão final: os resultados obtidos pelos diversos grupos eram apresentados ao grande grupo. Os pequenos quadros brancos também eram utilizados nesta etapa, pois permitiam que simultaneamente fossem visualizados os resultados dos diversos grupos.

Quatro atividades de modelagem foram desenvolvidas (Pêndulos; Sistema de Amortecimento Automotivo; Arquimedes e a Coroa do Rei; e Resfriamento de Sistemas), conforme constam em detalhes em Heidemann (2015) e em Heidemann, Araujo e Veit (2012b; 2013; 2015a). Dois aspectos diferenciavam substancialmente as atividades de modelagem conduzidas neste estudo das desenvolvidas no estudo exploratório que inspirou esta investigação (Heidemann, 2015; Heidemann, Araujo \& Veit, 2015a): i) foram conduzidos debates com os estudantes que tratavam explicitamente dos principais aspectos do processo de modelagem científica, segundo a concepção de Bunge e ii) foram definidos e compartilhados com os estudantes os conhecimentos que desejávamos que eles desenvolvessem durante as atividades. Julgamos que, especialmente em decorrência do estabelecimento de objetivos de aprendizagem: i) a professora da disciplina poderia ajustar suas ações especificamente para favorecer a apropriação por parte dos estudantes dos conhecimentos estabelecidos nos objetivos de aprendizagem e ii) os estudantes poderiam regular suas ações para alcançarem esses objetivos.

Tendo em vista as limitações de espaço, apresentamos sucintamente apenas a atividade "Sistema de Amortecimento Automotivo" e seus respectivos objetivos para exemplificar o tipo de situação trabalhada pelos estudantes durante a pesquisa. Os objetivos gerais e específicos de todas as atividades constam em Heidemann (2015). O objetivo geral dessa atividade era evidenciar que os modelos teóricos da Física são construções com o propósito de representar eventos reais, ou supostos como tais, e que as simplificações da realidade 
consideradas nesses modelos influenciam fortemente o delineamento de experimentos, pois procura-se utilizar arranjos experimentais em que os aspectos desconsiderados no modelo teórico de referência influenciem minimamente. Os objetivos específicos da atividade eram: a) representar a situação física de modo esquemático e à luz de algum campo conceitual específico da Física; b) delimitar objetos e eventos reais, ou supostos como tais, que compõem o sistema físico e sua vizinhança e que serão alvo de representação; c) dado um sistema físico, decidir quais dos seus traços-chave apreender; e d) dado um sistema físico previamente idealizado, decidir quais simplificações matemáticas serão assumidas, tais como: considerar relações lineares, desprezar ruídos etc.

Durante a discussão inicial, com o apoio de uma apresentação de slides (Heidemann, Araujo e Veit, 2014), a professora apresentou as seguintes questões:

"Que características devem ter os componentes do sistema de amortecimento de um automóvel? Como essas características influenciam nesse sistema? Quais os principais fatores que influenciam no amortecimento da oscilação de um corpo suspenso por uma mola que se move imerso em um fluido? Como esses fatores influenciam na oscilação desse corpo? Do que dependem esses fatores?".

Debatendo as ideias expostas pelos estudantes, a professora, juntamente com os alunos, concluíram que, para responder às questões apresentadas, seria útil entender melhor o movimento de um corpo preso a uma mola oscilando com amortecimento, que pode ser representado por meio do objeto-modelo de sistema massa-mola amortecido. Com esse objetivo, um dos grupos de estudantes, por exemplo, procurou investigar a influência das propriedades do fluido em que um sistema massa-mola é imerso sobre a intensidade do seu amortecimento. Para isso, esse grupo filmou o movimento de uma esfera quando ela oscilava verticalmente sustentada por uma mola imersa em diferentes líquidos (água, detergente, álcool gel, e misturas desses fluidos). Por meio de videoanálises realizadas com o software Tracker e fundamentados em um modelo teórico construído com base na mecânica newtoniana para representar os eventos investigados, os estudantes usaram planilhas eletrônicas para ajustar curvas exponenciais aos dados coletados, o que os possibilitou avaliar a constante de tempo dos amortecimentos pesquisados.

Um dos propósitos dessa atividade foi o de ressaltar aos estudantes que os experimentos de laboratório se constituem em eventos controlados, construídos com base em um modelo teórico de referência, que é uma representação simplificada de um evento real que, portanto, considera uma série de idealizações e aproximações. Com isso, pretendia-se envolver os estudantes com aspectos importantes da modelagem científica. Dependendo das características de cada atividade, alguns desses aspectos eram mais evidenciados do que outros.

Uma diferença importante entre as atividades desenvolvidas neste estudo e no estudo exploratório refere-se ao papel da professora na discussão final. Neste estudo, após o debate sobre os resultados obtidos pelos grupos de alunos, a professora fazia uma exposição apresentando uma possível solução para o problema proposto, promovendo uma discussão sobre o modelo teórico utilizado nessa solução, destacando as idealizações, as aproximações e os objetos da realidade considerados no modelo, assim como a teoria geral utilizada. $\mathrm{O}$ 
objetivo dessas apresentações era promover debates explícitos sobre os conceitos envolvidos no processo de modelagem científica.

$\mathrm{Na}$ próxima seção, apresentamos o contexto do estudo realizado, detalhando o perfil dos participantes e os tipos de atividades desenvolvidas na disciplina.

\section{CONTEXTO DO ESTUDO}

O caso investigado neste estudo foi uma turma matutina de uma disciplina experimental do segundo semestre de cursos de graduação em Física, abarcando conteúdos de oscilações mecânicas, fluidos e termodinâmica. A escolha dessa disciplina ocorreu em função dela abordar conteúdos de diferentes áreas da Física, possibilitando uma avaliação de atividades de modelagem em diferentes campos da Física. Na investigação, selecionamos como participantes do caso os estudantes matriculados na turma que tivessem, no mínimo, 50\% de presença e entregue, pelo menos, dois dos seis relatórios experimentais solicitados na disciplina. Esse critério eliminou dois dos sete alunos matriculados. Realizamos um estudo de caso incorporado (Yin, 2005), em que cada um dos cinco alunos participantes do estudo constituiu-se em uma unidade de análise, e ao final foram feitas análises cruzadas dos resultados alcançados por cada um. Eram três mulheres e dois homens, cujas idades variavam de 18 a 23 anos, sendo 20,6 anos a idade média. Uma breve descrição do perfil desses estudantes é exposta no Quadro 1.

Quadro 1 - Síntese do perfil dos participantes do estudo.

\begin{tabular}{|c|l|}
\hline Estudante & \multicolumn{1}{|c|}{ Perfil dos participantes do estudo } \\
\hline 1 & $\begin{array}{l}\text { Mulher, tinha } 18 \text { anos de idade. Cursava bacharelado em Física com ênfase } \\
\text { em Física Computacional. Era a primeira vez que cursava a disciplina } \\
\text { investigada. Até o semestre da investigação, cursou } 14 \text { disciplinas tendo } \\
\text { duas reprovações, mas também quatro conceitos máximos. Obteve o } \\
\text { conceito máximo na disciplina teórica que trata dos conteúdos de Física } \\
\text { envolvidos no estudo. Cursou a Educação Básica em escola pública, onde } \\
\text { não teve oportunidade de realizar atividades experimentais. }\end{array}$ \\
\hline \multirow{2}{*}{2} & $\begin{array}{l}\text { Homem, tinha } 23 \text { anos de idade. Cursava bacharelado em Física com ênfase } \\
\text { em Astrofísica. Era a primeira vez que cursava a disciplina investigada. } \\
\text { Bacharel em Química, solicitou e obteve equivalência de todas as outras } \\
\text { disciplinas experimentais do curso de Física, assim como de todas as } \\
\text { disciplinas teóricas de Física Geral. Simultaneamente ao bacharelado em } \\
\text { Física, cursava mestrado em Química. No Ensino Médio, fez curso técnico em } \\
\text { Química, onde realizava atividades de laboratório com frequência. }\end{array}$ \\
\hline \multirow{1}{*}{3} & $\begin{array}{l}\text { Mulher, tinha 22 anos de idade. Cursava bacharelado em Física com ênfase } \\
\text { em Astrofísica. Antes de ingressar no curso de Física, cursou bacharelado em } \\
\text { Letras durante dois anos, onde foi reprovada por falta de frequência em oito } \\
\text { das 10 disciplinas cursadas. Era repetente também na disciplina } \\
\text { experimental em que foi realizada a investigação, tendo sido reprovada por } \\
\text { falta de frequência na primeira vez que cursou. Foi reprovada também duas } \\
\text { vezes na disciplina teórica que trata dos conteúdos de Física envolvidos no } \\
\text { estudo. Entregou todas as tarefas solicitadas na disciplina com grande } \\
\text { atraso. No semestre posterior ao estudo, ingressou no curso de Design. } \\
\text { Cursou a Educação Básica em escola particular, onde não teve oportunidade } \\
\text { de realizar atividades experimentais. }\end{array}$ \\
\hline
\end{tabular}




\begin{tabular}{|c|l|l|}
\hline \multirow{5}{*}{4} & $\begin{array}{l}\text { Homem, tinha } 21 \text { anos de idade. Cursava licenciatura em Física, e era a } \\
\text { primeira vez que cursava a disciplina experimental em que foi realizada a } \\
\text { investigação. Até o semestre da investigação, cursou } 28 \text { disciplinas tendo } 10 \\
\text { reprovações, sendo quatro por falta de frequência. Foi reprovado na } \\
\text { disciplina teórica que trata dos conteúdos de Física envolvidos no estudo no } \\
\text { semestre em que participou da pesquisa. Cursou a Educação Básica em } \\
\text { escola pública, onde não teve oportunidade de realizar atividades } \\
\text { experimentais. }\end{array}$ \\
\hline \multirow{5}{5}{} & $\begin{array}{l}\text { Mulher, tinha } 19 \text { anos de idade. Cursava licenciatura em Física. Antes de } \\
\text { ingressar no curso de Física, fez cinco disciplinas do curso de Medicina } \\
\text { Veterinária, sendo reprovada em três delas. Era a primeira vez que cursava a } \\
\text { disciplina experimental em que foi realizada a investigação. No semestre } \\
\text { seguinte à investigação, trocou de curso: saiu da licenciatura em Física e foi } \\
\text { para o bacharelado em Física com ênfase em Nanotecnologia. Cursou a } \\
\text { Educação Básica em escola pública, onde teve oportunidade de realizar } \\
\text { atividades experimentais que julga bastante positivas. }\end{array}$ \\
\hline
\end{tabular}

A disciplina ministrada contou com 18 aulas, uma por semana, de 1 hora e 40 minutos, divididas em: i) quatro atividades de modelagem; ii) duas atividades experimentais tradicionais; e iii) quatro demonstrações experimentais.

Na próxima seção, debatemos os procedimentos metodológicos adotados na investigação.

\section{METODOLOGIA DE PESQUISA}

Assim como no estudo exploratório que inspirou o delineamento desta investigação (Heidemann, Araujo e Veit, 2015a), tendo em vista as características das atividades de modelagem, optamos por desenvolver um estudo de caso seguindo as orientações metodológicas de Yin (2005, 2011). A metodologia de estudo de casos de Yin (idem) se mostra adequada para pesquisas em que os casos investigados não apresentam limites bem demarcados, como ocorreu neste estudo. Devido ao caráter aberto das atividades, as ações dos participantes seriam complexas, tornando inviável o uso de metodologias de pesquisa que implicam a desconstrução das ações dos indivíduos em um conjunto de eventos isolados. Dos diferentes tipos de casos destacados pelo autor (decisivos, raros, típicos, reveladores e longitudinais), optamos por investigar um caso típico. Por isso, escolhemos uma turma matutina da disciplina em que faríamos o estudo.

Seguindo as orientações de Yin (idem), buscamos neste estudo explanatório testar proposições teóricas previamente traçadas em um estudo exploratório. Delineamos então múltiplas fontes de evidência para o estudo baseando-nos sempre em uma lógica que uniria os dados coletados com as proposições teóricas que seriam testadas. Analisando as proposições teóricas que desejávamos avaliar, estabelecemos as seguintes fontes de evidência para o estudo:

a) dois questionários aplicados como testes iniciais. O Questionário 1 foi respondido pelos estudantes presencialmente na primeira aula da disciplina. Com ele, procuramos avaliar o domínio dos estudantes sobre o campo conceitual da modelagem didático-científica. O Questionário 2 foi respondido online pelos estudantes na primeira semana de aula em horário extraclasse. Nele, os estudantes manifestaram, entre outras coisas, suas experiências em disciplinas 
experimentais e suas expectativas para a disciplina que se iniciava, o que possibilitou uma melhor compreensão sobre suas crenças sobre atividades experimentais. Além disso, eles apontaram seus níveis de concordância com uma série de afirmativas que possibilitavam inferências sobre as suas atitudes em relação às aulas experimentais. Detalhes sobre esses e outros instrumentos de avaliação podem ser consultados em Heidemann (2015);

b) dois questionários aplicados como testes finais. O primeiro deles, idêntico ao Questionário 1, foi respondido presencialmente pelos estudantes no penúltimo dia de aula da disciplina. O segundo, uma variante do Questionário 2, foi aplicado no último dia de aula. A principal diferença entre os questionário aplicados no início e no final da disciplina se refere a uma questão utilizada para mensurar as atitudes dos estudantes. No teste final, ela foi desmembrada com o objetivo de possibilitar que os alunos expressassem suas opiniões: i) sobre atividades experimentais tradicionais; e ii) sobre as atividades de modelagem realizadas na disciplina;

c) filmagens das discussões finais;

d) relatórios produzidos pelos alunos sobre cada uma das atividades realizadas. Um documento contendo instruções para a confecção de relatórios foi entregue aos estudantes no quarto dia de aula;

e) gravações de entrevistas semiestruturadas realizadas com os estudantes seis meses após o final da disciplina. Essas gravações e as filmagens das discussões finais possibilitaram a coleta de dados sobre as ações dos estudantes em situação;

f) um caderno de campo, onde o pesquisador registrou os eventos pertinentes no contexto da investigação.

Baseados nos dados coletados com as diversas fontes de evidências expostas apresentamos na próxima seção os resultados do estudo.

\section{RESULTADOS}

Com o intuito de tornar clara a exposição dos resultados, apresentamo-los divididos em seções que abordam cada uma das questões de pesquisa e suas respectivas proposições teóricas. Em Heidemann (2015), esses resultados são apresentados com maior profundidade, divididos para cada uma das unidades de análise da investigação, ou seja, para cada um dos estudantes participantes da pesquisa. Neste artigo, nos limitamos a apresentar uma síntese dos principais resultados relacionados com cada uma das questões investigadas.

Como as atividades experimentais com enfoque no processo de modelagem científica conduzidas influenciaram as crenças e as atitudes dos estudantes em relação às atividades experimentais?

Proposições teóricas testadas: Atividades experimentais com enfoque no processo de modelagem científica contribuem para que os estudantes construam atitudes mais positivas em relação a atividades experimentais, em decorrência da adoção de crenças que salientam os aspectos positivos dessas atividades. A 
adoção dessas crenças ocorre porque as atividades são frutíferas para defrontar os estudantes com problemas abertos, dando liberdade para que eles realizem autênticas investigações e que dirijam seus esforços para dirimirem suas curiosidades e dificuldades conceituais durante as aulas.

Os dados coletados na investigação demonstraram que, dos cinco participantes do estudo, três construíram atitudes mais positivas em relação às atividades de modelagem, enquanto que outros dois apresentaram atitudes mais favoráveis às atividades experimentais tradicionais. Uma das evidências de tal resultado consiste nas atitudes dos estudantes mensuradas por meio do questionário respondido online no início e no final da disciplina. Nele, foi solicitado que os participantes apresentassem seus níveis de concordância com oito afirmativas como, por exemplo: "Não me interesso pelas atividades desenvolvidas durante as aulas de laboratório de Física". Convertemos então as respostas "discordo fortemente", "discordo", "indeciso ou sem opinião", "concordo" e "concordo fortemente", ou seja, os níveis de concordância dos estudantes, nos valores 1, 2, 3, 4 e 5, respectivamente. As atitudes dos participantes foram mensuradas pelo somatório de suas respostas para cada uma das oito afirmativas presentes no questionário. Previamente, o conjunto dessas oito afirmativas foi validado por meio de uma aplicação do questionário com um grupo de 124 estudantes de disciplinas experimentais introdutórias de Física. 0 coeficiente de fidedignidade alfa de Cronbach (Field, 2009) obtido foi de 0,85 , o que pode ser entendido como uma evidência de que o conjunto de afirmativas possui validade interna.

Após serem normalizadas para valores entre 0 e 10, a média das atitudes dos participantes em relação às atividades experimentais tradicionais no início da disciplina foi de 7,6. Cabe ressaltar que, ainda que o pesquisador tenha solicitado diversas vezes que os estudantes respondessem ao Questionário 2 no início da disciplina, a Estudante 3 não o respondeu. No teste final, foram mensuradas as atitudes dos participantes tanto em relação às atividades experimentais tradicionais, cuja média foi de 7,1 , quanto em relação às atividades de modelagem, com média de 7,8. A Tabela 1 apresenta as atitudes mensuradas para cada um dos participantes.

Tabela 1 - Atitudes dos participantes em relação às atividades experimentais tradicionais e às atividades de modelagem.

\begin{tabular}{|c|c|c|c|}
\hline Estudante & Teste Inicial & \multicolumn{2}{|c|}{ Teste Final } \\
\cline { 2 - 4 } & $\begin{array}{c}\text { Atitude em relação às } \\
\text { atividades } \\
\text { experimentais } \\
\text { tradicionais }\end{array}$ & $\begin{array}{c}\text { Atitude em relação às } \\
\text { atividades } \\
\text { experimentais } \\
\text { tradicionais }\end{array}$ & $\begin{array}{c}\text { Atitude em relação às } \\
\text { atividades de } \\
\text { modelagem }\end{array}$ \\
\hline 1 & 7,5 & 6,2 & 8,1 \\
\hline 2 & 6,6 & 7,5 & 6,2 \\
\hline 3 & - & 3,4 & 6,9 \\
\hline 4 & 7,2 & 10,0 & 7,8 \\
\hline 5 & 9,1 & 8,4 & 9,7 \\
\hline Média & 7,6 & 7,1 & 7,8 \\
\hline
\end{tabular}

Os dados da Tabela 1 mostram que as estudantes 1, 3 e 5 tinham atitudes mais favoráveis às atividades de modelagem, enquanto os estudantes 2 e 4 , às 
atividades experimentais tradicionais. Dados coletados em outras questões respondidas pelos estudantes ao final da disciplina corroboram esse resultado. Por exemplo, o Estudante 4, quando questionado sobre o desenvolvimento das atividades de modelagem na disciplina, disse: "Eu gostaria que houvesse mais experimentos. Talvez o tempo melhor aproveitado, ou ainda que fosse mais instruído: 'façam isso, assim e assim'". Desse modo, o participante evidenciou um sentimento desfavorável em relação às atividades de modelagem. Por outro lado, a Estudante 5 demonstra ter uma atitude positiva às atividades de modelagem, pois, quando questionada sobre a sua preferência entre as atividades de modelagem e as atividades tradicionais, disse:

\footnotetext{
As atividades de modelagem são melhores porque temos mais liberdade com o experimento. Podemos, a partir de um objetivo, pensar como faríamos para resolver o problema ao invés de todos fazerem o mesmo experimento já estipulado. Numa aula com modelagem cada grupo pode fazer 'o que quiser' e no final podemos comparar os resultados, avaliar qual(is) dos modelos serviu melhor para um determinado fenômeno físico. Já na aula tradicional, todos fazem a mesma coisa, apenas coletamos os dados sem, geralmente, comparar com os dos outros grupos.
}

As manifestações dos estudantes na entrevista realizada ao final da disciplina também evidenciaram uma divisão em suas atitudes. O Estudante 1, por exemplo, evidenciou um sentimento favorável às atividades de modelagem dizendo: "A vantagem disso [do enfoque no processo de modelagem] é que se aprende mais e acaba sendo algo mais desafiador, sendo, portanto, mais legal". De modo semelhante, a Estudante 3 afirmou: "É mais legal tu ter essa possibilidade de tentar desenvolver o teu jeito de fazer [...] Acho que tu aprende uma parte maior do processo quando tu tem essa liberdade". Por outro lado, quando questionado sobre a liberdade da qual dispunha nas atividades, o Estudante 2 afirmou: "Não vejo nada de muito proveitoso. Eu acho que liberdade demais, falta um norte para o pessoal".

É importante ressaltar também que os estudantes 1, 2 e 3 manifestaram duras críticas às atividades experimentais tradicionais. O Estudante 2, por exemplo, disse em entrevista que, quando realizava atividades tradicionais, acabava "perdendo a paciência, porque as coisas demoram, as coisas enchiam o saco, de fazer síntese, de as coisas serem muito matadas". Já a Estudante 3 disse: "[...] tu não precisava fazer muita coisa. [...] Era meio que uma 'matação'".

Quanto às suas crenças sobre as atividades de modelagem, ou seja, sobre os conhecimentos dos participantes que moldam suas atitudes frente às atividades de modelagem, identificamos quatro crenças salientes que destacamos na sequência.

A liberdade que dispunham para delinear e executar seus experimentos nas atividades de modelagem foi apreciada positivamente pelas estudantes 1,3 e 5 . A Estudante 1, por exemplo, disse em entrevista: "A vantagem de tu ser mais liberal é que tu mais ou menos vê a parte que tu gosta mais, e tu vai mais atrás procurar. Quando já tem tudo pronto, tem tudo feito, tu nem 'se puxa' muito e faz mais ou menos. [...] Tu tinha que te dedicar mais". Por outro lado, os estudantes 2 e 4 evidenciaram não apreciar essa liberdade. 0 Estudante 2, por exemplo, disse em entrevista: "Eu acho que faltou um pouco de orientação para ter boas ideias. Eu acho que o pessoal teve ideias meio bestas em alguns experimentos, em algumas coisas". 
O vínculo entre os conteúdos de Física e eventos cotidianos promovidos pelas atividades de modelagem foi destacado nas manifestações das estudantes 1 e 5. A Estudante 5, por exemplo, disse: "Eu acho que [as atividades de modelagem] servem bastante para relacionar fenômenos físicos com as coisas que a gente vê".

Os debates sobre as investigações experimentais promovidos nas discussões finais foram destacados pelos estudantes 4 e 5. O Estudante 4, por exemplo, "Tu olhava diretamente o resultado dos outros. [...] Era bem interessante. [...] A vantagem é que tu pode discutir com os próprios colegas". Por outro lado, o estudante também manifestou que tinha dificuldades de se expressar em frente aos colegas dizendo: "Era um pouco embaraçoso".

O longo tempo demandado para a realização das atividades de modelagem foi considerado uma limitação das atividades de modelagem pelos estudantes 2 , 4 e 5. Por exemplo, o Estudante 2 afirmou em entrevista que, devido à liberdade que os participantes tinham para delinear e executar suas investigações, as atividades de modelagem deveriam ser realizadas com mais tempo. Ele disse: "Precisaria de mais tempo do que chegar numa aula e já na semana seguinte começar um experimento".

Concluindo, podemos dizer que não temos evidências suficientes para afirmar que a proposição teórica avaliada foi ou não corroborada. Podemos afirmar, no entanto, que os dados coletados demonstram que os três participantes do sexo feminino construíram atitudes positivas às atividades conduzidas, enquanto os do sexo masculino não gostaram das aulas, principalmente em função da liberdade que tinham para tomar decisões em suas investigações, que foi considerada excessiva por eles. Esses resultados vão ao encontro dos de Brewe et al. (2010), que observaram que as atividades de modelagem conduzidas pelos pesquisadores favoreceram a participação de estudantes pertencentes a algumas minorias (hispânicos, negros e mulheres). Podemos concluir também que a liberdade da qual os estudantes dispunham nas atividades para delinear e executar suas investigações foi um aspecto muito presente nas crenças dos estudantes. Enquanto as três estudantes participantes apontaram tal liberdade como algo positivo, contribuindo para que elas tivessem atitudes positivas frente às atividades de modelagem, os outros dois participantes do estudo evidenciaram que se sentiam desnorteados nas investigações, o que colaborou para que esses estudantes não construíssem atitudes tão positivas em relação às atividades. Em suma, as principais crenças que influenciaram na construção das atitudes dos estudantes em relação às atividades de modelagem estão associadas com: i) a liberdade para delinear e executar experimentos nas investigações; ii) a construção de conexões entre os conteúdos de Física e eventos cotidianos promovida nas discussões inicial e final; iii) os debates sobre investigações experimentais conduzidos nas investigações e discussões finais; e iv) a demanda de bastante tempo e esforço para realizarem as investigações e confeccionarem relatórios.

Como atividades experimentais focadas no processo de modelagem científica influenciam o domínio do campo conceitual da modelagem didático-científica por parte dos estudantes? 
Procurando investigar o nível do domínio dos estudantes sobre o campo conceitual da modelagem didático-científica, buscamos avaliar a compreensão deles sobre diferentes conceitos e situações relacionadas com esse campo conceitual, que denominamos de situações de modelagem. Construímos duas proposições teóricas para serem avaliadas com essa segunda questão de pesquisa. No que segue, apresentaremos essas proposições juntamente com as evidências coletadas para avaliá-las. A primeira proposição teórica é exposta abaixo.

Proposição teórica testada: Atividades experimentais com enfoque no processo de modelagem científica contribuem para que os estudantes desenvolvam conhecimentos relacionados com o campo conceitual da modelagem didático-científica, porque elas são frutíferas para dar sentido aos conceitos fundamentais do campo conceitual da modelagem didático-científica, possibilitando que os estudantes compartilhem significados para esses conceitos que sejam coerentes com as concepções epistemológicas contemporâneas.

Como mencionado na seção "Referencial Teórico-Metodológico", o campo conceitual da modelagem didático-científica envolve uma série de conceitos como, por exemplo, de idealização, aproximação, domínio de validade e grau de precisão. Com o objetivo de aprofundar a análise conduzida, decidimos nos focar neste estudo na investigação das concepções dos participantes sobre três conceitos mais inclusivos e centrais do campo conceitual da modelagem didáticocientífica: modelo, teoria e modelagem.

As evidências coletadas mostraram que os estudantes apresentavam, mesmo no final da disciplina, concepções sobre o conceito de modelo bastante confusas e variadas. A análise dos dados possibilitou concluir que os estudantes possuíam cinco concepções distintas, que são sintetizadas no Quadro 2. No que segue, exemplificamos momentos em que três dessas concepções foram evidenciadas.

A concepção de que os modelos são descrições simplificadas de eventos físicos, ou seja, na nomenclatura bungeana, um objeto-modelo, foi evidenciada por dois estudantes em algum momento da investigação. A Estudante 3, por exemplo, em entrevista, disse: "O modelo seria tu considerar, tipo, o pêndulo uma massa pontual e essas idealizações".

A concepção de modelos como equações que descrevem o comportamento de eventos físicos específicos foi identificada nas manifestações de dois estudantes. Por exemplo, no primeiro relatório da Estudante 1, ela afirmou: "Para calcular o período do pêndulo simples para pequenas amplitudes, usamos o modelo $T=2 \pi \cdot \sqrt{1 / g}$ ". De modo semelhante, questionada sobre um modelo que poderia ser utilizado para resolver um problema do questionário respondido ao final da disciplina, sua resposta foi: "Equações do movimento retilíneo uniformemente variado". Em entrevista, a estudante também demonstrou entender que os modelos científicos são equações: "Modelo... Seria uma equação maior? [...] É uma equação que tu modificou ela, mas conforme a questão".

A concepção de que os modelos são representações simplificadas de eventos físicos também foi evidenciada pela Estudante 1. Por exemplo, ela discordou, no questionário respondido ao final da disciplina, das proposições que diziam que "modelos científicos podem ser entendidos como descrições fiéis de aspectos da 
realidade" e que "modelos científicos devem fornecer descrições exatas de sistemas físicos". Outra evidência de que a estudante compreende que modelos são idealizados foi identificada em entrevista. Questionada sobre as características dos modelos científicos, a estudante disse: "Eu esqueci [pausa] que nem tu despreza... [longa pausa] as simplificações! É! É isso aí. É que nem quando tu despreza a resistência do ar".

Quadro 2 - Concepções dos estudantes sobre o conceito de modelo. As células com $\sqrt{ }$ apontam que o estudante evidencia compartilhar da concepção indicada na coluna ao menos uma vez na investigação.

\begin{tabular}{|c|c|c|c|c|c|}
\hline \multirow[b]{2}{*}{ 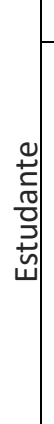 } & \multicolumn{5}{|c|}{ Concepção sobre o conceito de modelo: Modelos são... } \\
\hline & $\begin{array}{c}\text {...descrições } \\
\text { simplificadas } \\
\text { de eventos } \\
\text { físicos, ou } \\
\text { seja, na } \\
\text { nomenclatura } \\
\text { bungeana, um } \\
\text { objeto- } \\
\text { modelo. }\end{array}$ & $\begin{array}{c}\text {...representações } \\
\text { simplificadas de } \\
\text { eventos físicos, } \\
\text { ou seja, na } \\
\text { nomenclatura } \\
\text { bungeana, um } \\
\text { modelo teórico. }\end{array}$ & $\begin{array}{c}\text {...arranjos } \\
\text { concretos } \\
\text { construídos } \\
\text { com o } \\
\text { intuito de } \\
\text { reproduzir } \\
\text { eventos } \\
\text { físicos. }\end{array}$ & $\begin{array}{c}\text {...leis gerais } \\
\text { que podem } \\
\text { ser utilizadas } \\
\text { para } \\
\text { representar } \\
\text { uma série de } \\
\text { situações. }\end{array}$ & $\begin{array}{c}\text {...equações } \\
\text { que } \\
\text { descrevem o } \\
\text { comportamen } \\
\text { to de eventos } \\
\text { físicos } \\
\text { específicos. }\end{array}$ \\
\hline 1 & & $\checkmark$ & & & $\checkmark$ \\
\hline 2 & $\checkmark$ & & & & \\
\hline 3 & $\checkmark$ & & & & \\
\hline 4 & & & & $\checkmark$ & $\checkmark$ \\
\hline 5 & & & $\checkmark$ & & \\
\hline
\end{tabular}

Sobre o conceito de teoria, também identificamos cinco concepções diferentes entre os estudantes, que são sintetizadas no Quadro 3. Por exemplo, coletamos evidências de que o Estudante 2 entendia que teorias são equações gerais que representam eventos físicos específicos, como é evidenciado pela transcrição abaixo de um diálogo durante uma entrevista.

Pesquisador: O que é o modelo de pêndulo simples?

Estudante 2: É um ponto de massa na extremidade de um fio ideal, inextensível, desprovido de massa que oscila em torno da posição de equilíbrio de forma sem atrito com o ar.

Pesquisador: Se eu te digo isso aqui [é apresentada a equação ], isso aqui é o modelo de pêndulo simples ou eu já estou na teoria?

Estudante 2: Já está na teoria.

O mesmo estudante, em outro momento de sua entrevista, demonstrou compreender que teorias são visões ontológicas sobre a natureza. Ele disse: "Teoria atômica. Nós temos diversos modelos, uns melhores, outros piores, uns rejeitados, de como é o átomo. [...] A teoria atômica é que a natureza é composta de átomos e do que eles são compostos".

Uma das concepções adotadas pela Estudante 5 é de que as teorias são descrições simplificadas de eventos físicos. Ele exemplificou dizendo: 
Na Física teórica, o comportamento da onda é assim [gesticula com as mãos um movimento ondulatório]. Aí a gente vai lá, faz o experimento, e não é bem assim. Algumas coisas são diferentes. Mas claro, tem coisas que a gente não leva em conta, que na teoria a gente pode abstrair, porque não está lá, mas quando a gente tá fazendo de verdade, não tem como negar que o ar está aqui, que a gravidade está agindo sobre aquilo, que em teoria às vezes dá pra dizer que não está ali, e aí as coisas funcionam.

A Estudante 1 apresentou uma evidência de que entende que as teorias são leis gerais sobre a natureza quando disse: "Teoria é mais geral e não é uma coisa mais específica". Em outro momento, no entanto, ela evidencia compreender que as teorias são equações gerais que descrevem comportamentos da natureza. Ela disse: "Tu tem a situação, tu sabe mais ou menos a teoria, e tu vai modificando a equação adaptando ela ao experimento, até tu chegar no modelo que explique o resultado".

Quadro 3 - Concepções dos estudantes sobre o conceito de teoria. As células com $\checkmark$ apontam que o estudante evidencia compartilhar da concepção indicada na coluna ao menos uma vez na investigação.

\begin{tabular}{|c|c|c|c|c|c|}
\hline \multirow[b]{2}{*}{ 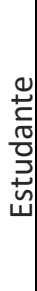 } & \multicolumn{5}{|c|}{ Concepção sobre o conceito de teoria: Teorias são... } \\
\hline & $\begin{array}{c}\text {...lei gerais } \\
\text { sobre o } \\
\text { comportamento } \\
\text { da natureza. }\end{array}$ & $\begin{array}{c}\text {...equações gerais } \\
\text { que descrevem } \\
\text { comportamentos } \\
\text { da natureza. }\end{array}$ & $\begin{array}{l}\text {...equações } \\
\text { que } \\
\text { representam } \\
\text { eventos } \\
\text { físicos } \\
\text { específicos. }\end{array}$ & $\begin{array}{c}\text {...são } \\
\text { descrições } \\
\text { simplificadas } \\
\text { de eventos } \\
\text { físicos. }\end{array}$ & $\begin{array}{c}\text {...visões } \\
\text { ontológicas } \\
\text { sobre a } \\
\text { natureza. }\end{array}$ \\
\hline 1 & $\sqrt{ }$ & $\sqrt{ }$ & & & \\
\hline 2 & & & $\sqrt{ }$ & & $\checkmark$ \\
\hline 3 & & $\sqrt{ }$ & & & \\
\hline 4 & & & & $\sqrt{ }$ & \\
\hline 5 & $\sqrt{ }$ & & $\sqrt{ }$ & $\sqrt{ }$ & \\
\hline
\end{tabular}

Quanto ao conceito de modelagem, os estudantes 1, 2, 4 e 5 demonstraram restringir o uso de tal conceito para se referir ao processo de construção de modelos. As diferenças entre as concepções desses estudantes são decorrentes das distintas compreensões que eles têm sobre os conceitos de modelo e de teoria. Por exemplo, em decorrência do seu entendimento de que modelos são descrições simplificadas de eventos físicos, o Estudante 2 apresenta uma concepção sobre o processo de modelagem vinculada com a construção de um objeto-modelo. Em entrevista, ele afirmou que modelagem "é tu tentar pegar um fenômeno de difícil compreensão, de difícil explicação e tentar encontrar os elementos básicos, o que é elementar para que ele possa descrever o comportamento que seja semelhante ao que é obtido". Destaca-se que os estudantes 1, 2, 4 e 5 não vinculam o conceito de modelagem com o processo de contrastação empírica dos modelos científicos. O Estudante 3, de modo diferente, inclui no processo de modelagem 0 ato de validar modelos, evidenciando uma concepção mais completa sobre esse processo. Em entrevista, ela disse: 
precisa. [...] Acho que tu pode prever como esse modelo vai se comportar utilizando alguma teoria e daí tu pode testar em laboratório, fazer um experimento, [avaliar] como esse modelo se adequa.

Os resultados mostram que as mudanças na concepção dos estudantes sobre os conceitos de modelo, de teoria e de modelagem foram bastante tímidas. Nas entrevistas realizadas ao final da disciplina pode-se identificar estudantes com concepções superficiais sobre os conceitos investigados. Esses resultados, portanto, não fornecem apoio empírico para a proposição teórica testada na investigação, pois a realização de debates explícitos sobre metamodelagem não foram suficientes para que os estudantes compreendessem adequadamente o significado dos principais conceitos do campo conceitual da modelagem didáticocientífica.

Passamos agora a apresentar as evidências coletadas na investigação relacionadas com a segunda proposição teórica da segunda questão de pesquisa, que é apresentada abaixo.

Proposição teórica testada: Atividades experimentais com enfoque no processo de modelagem científica contribuem para que os estudantes desenvolvam conhecimentos relacionados com o campo conceitual da modelagem didático-científica, porque elas são frutíferas para defrontar os estudantes com situações que envolvem conceitos e esquemas de ação relacionados com esse campo conceitual.

Os resultados que passamos a descrever mostram que o desenvolvimento de competências relacionadas ao campo conceitual da modelagem didáticocientífica por parte dos estudantes foi lento, penoso e tímido. No que segue, destacaremos os principais avanços e dificuldades dos estudantes quando defrontados com situações de modelagem, partindo da análise dos 18 relatórios produzidos pelos estudantes e posteriormente os relacionamos com dados provenientes de outras fontes de evidências. A análise dos relatórios levou em conta os itens especificados no Quadro 4.

Cada um dos itens de avaliação dos relatórios foram divididos em subcritérios que conjuntamente constituíram um protocolo de avaliação (detalhes podem ser consultados em Heidemann, 2015). Em cada relatório analisado, foi atribuído o número 1 ? 0 ou 0 ?]? ? ? avaliação indicando se ele é atendido ou não, respectivamente. A avaliação de cada critério do protocolo foi contabilizado como a média dos subcritérios utilizados para analisá-los. A Tabela 2 sintetiza as avaliações dos 18 relatórios produzidos pelos estudantes.

Quadro 4 - Itens avaliados nos relatórios produzidos pelos estudantes e suas descrições.

\begin{tabular}{|c|l|}
\hline $\begin{array}{c}\text { Itens sob } \\
\text { análise }\end{array}$ & $\begin{array}{l}\text { Descrições: Análise do relatório sob o ponto de vista da qualidade da } \\
\text { exposição... }\end{array}$ \\
\hline Objetivos & $\begin{array}{l}\text {...dos objetivos das investigações, avaliando se são expostos de forma } \\
\text { relacionada com o uso, a construção ou exploração de um modelo } \\
\text { científico. }\end{array}$ \\
\hline Teoria Geral & $\begin{array}{l}\text {...da teoria geral que ampara a construção do(s) modelo(s) teórico(s) } \\
\text { que dirige(m) a investigação. }\end{array}$ \\
\hline Simplificações & $\begin{array}{l}\text {...das simplificações da realidade consideradas no(s) modelo(s) } \\
\text { teórico(s) que dirige(m) a investigação. }\end{array}$ \\
\hline Referentes & ...dos objetos da realidade considerados no(s) modelo(s) teórico(s) que \\
\hline
\end{tabular}




\begin{tabular}{|c|l|}
\hline $\begin{array}{c}\text { Relação Teoria- } \\
\text { Experimento }\end{array}$ & $\begin{array}{l}\text { dirige(m) a investigação. } \\
\text { com a escolaçes do(s) modelo(s) teórico(s) que dirige(m) a investigação } \\
\text { dados realizada. }\end{array}$ \\
\hline Representações & $\begin{array}{l}\text {...da análise dos dados experimentais realizada por meio da } \\
\text { interpretação dos mesmos dispostos por meio de ferramentas de } \\
\text { representação adequadas com base no(s) modelo(s) teórico(s) que } \\
\text { dirige(m) a investigação. }\end{array}$ \\
\hline Fonte de & $\begin{array}{l}\text {...das fontes de incerteza dos dados coletados, avaliando se são } \\
\text { destacadas as imprecisões dos instrumentos utilizados assim como } \\
\text { problemas no controle de variáveis que são realizadas com o propósito } \\
\text { de amenizar a influência de aspectos não considerados no(s) modelo(s) } \\
\text { teórico(s) que dirige(m) a investigação. }\end{array}$ \\
\hline Conclusões & $\begin{array}{l}\text {...das conclusões da investigação, avaliando se as mesmas são } \\
\text { amparadas em confrontações entre dados experimentais e predições } \\
\text { baseadas em modelos científicos. }\end{array}$ \\
\hline
\end{tabular}

Tabela 2 - Médias das avaliações dos relatórios confeccionados pelos estudantes sobre as atividades de modelagem científica conduzidas.

\begin{tabular}{|c|c|c|c|c|c|c|c|c|c|}
\hline $\begin{array}{l}\text { Atividade de } \\
\text { Modelagem }\end{array}$ & 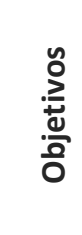 & 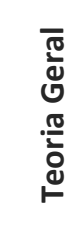 & & & 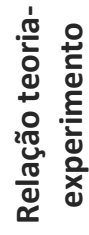 & 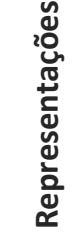 & 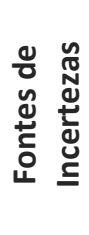 & 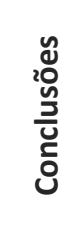 & 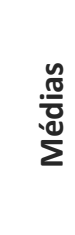 \\
\hline Pêndulos & 0,70 & 0,20 & 0,45 & 0,45 & 0,40 & 0,70 & 0,25 & 0,74 & 0,49 \\
\hline $\begin{array}{c}\text { Sistema de } \\
\text { Amortecimento } \\
\text { Automotivo }\end{array}$ & 0,63 & 0,63 & 0,19 & 0,75 & 0,50 & 0,69 & 0,56 & 0,75 & 0,59 \\
\hline $\begin{array}{c}\text { Arquimedes e a } \\
\text { Coroa do Rei }\end{array}$ & 0,50 & 0,85 & 0,65 & 0,50 & 0,53 & 0,75 & 0,35 & 0,74 & 0,61 \\
\hline $\begin{array}{l}\text { Resfriamento } \\
\text { de Sistemas }\end{array}$ & 0,85 & 0,95 & 0,50 & 0,50 & 0,40 & 0,95 & 0,10 & 0,47 & 0,58 \\
\hline
\end{tabular}

Os dados da Tabela 2 evidenciam que, ainda que os estudantes tenham apresentado avanços e retrocessos em todos os critérios de avaliação, no cômputo geral, poucas mudanças ocorreram. O principal avanço observado nos relatórios refere-se à qualidade das exposições das teorias gerais que ampararam os modelos teóricos de referência das investigações, identificado nos relatórios dos estudantes 1, 4 e 5. Por exemplo, no relatório da atividade "Pêndulos", o primeiro da disciplina, a Estudante 1 meramente expôs a equação que foi utilizada, dizendo que o seu referencial teórico era a equação. Já no último relatório (da atividade "Resfriamento de Sistemas"), a estudante inicialmente expôs discussões sobre trocas de energia por calor, por irradiação e por evaporação, para somente então apresentar o modelo teórico que dirigiu sua investigação. Desse modo, a estudante demonstra ter aprimorado seus esquemas de ação relacionados com o enfrentamento de situações em que precisa construir um modelo teórico à luz de um campo conceitual específico da Física. Essa evolução é explicada, parcialmente, pela insistência da professora da disciplina em solicitar aos estudantes um melhor esclarecimento sobre as origens teóricas dos modelos que dirigiam as suas investigações. Em entrevista, 
questionada sobre o motivo pelo qual não destacava a teoria geral utilizada no seu primeiro relatório, a Estudante 1 argumentou: "Porque até então a gente só tinha feito um relatório na vida. Acho que é uma questão de achar que o mais importante é explicar detalhadamente o que foi feito. [...] Só coloquei o que eu achava necessário".

A seleção de ferramentas de representação adequadas é outro aspecto no qual foram identificados avanços nos relatórios dos estudantes 1,3 e 5 . A Estudante 1, por exemplo, optou por apresentar seus dados no relatório da primeira atividade de modelagem, que se referiam ao período de um pêndulo em função da sua amplitude, em uma tabela. A exposição desses dados em um gráfico seria uma escolha mais adequada para analisar o aumento do período do pêndulo em função da sua amplitude. Já no relatório da última atividade ("Resfriamento de Sistemas"), a estudante optou por expor os dados coletados no seu experimento na forma de gráficos, o que é uma escolha apropriada para facilitar a contrastação da predição da Lei de Resfriamento de Newton com os dados experimentais. A estudante demonstrou ter mobilizado um invariante operatório adequado para a situação enfrentada, mostrando-se capaz de representar um evento físico de forma esquemática à luz de um modelo teórico da Física.

Quanto às dificuldades enfrentadas pelos participantes, pode-se perceber que apontar as simplificações da realidade consideradas nas suas investigações era uma tarefa difícil para os estudantes $1,3,4$ e 5. No relatório da atividade "Sistema de Amortecimento Automotivo", a Estudante 1, por exemplo, afirma que no modelo teórico do sistema massa-mola amortecido, utilizado por ela na sua investigação, "idealizamos que a massa da mola era desprezível, que a massa da esfera era uniforme, que não há atrito entre a mola e o suporte rígido e que a força gravitacional é desprezível". No entanto, o modelo utilizado pela estudante não pressupõe uniformidade da massa do corpo suspenso e não despreza a força gravitacional. Além disso, uma simplificação importante considerada nesse modelo, mas não destacada por ela, é a de baixas velocidades de oscilação do sistema. Nesse episódio, pode-se identificar, portanto, dois tipos de dificuldades enfrentados pela estudante: i) ela aponta mais simplificações da realidade do que efetivamente foram consideradas no modelo utilizado; e ii) não destaca uma simplificação da realidade importante que foi considerada nesse modelo. Problemas dessa natureza foram identificados em todos os relatórios. Desse modo, ela evidencia não possuir esquema de ação que lhe permita enfrentar com sucesso situações que demandam a identificação das simplificações da realidade consideradas em um modelo teórico.

A dificuldade de apontar simplificações também se manifesta em sua resposta sobre simplificações da realidade consideradas em um problema que envolve o atropelamento de uma criança por um automóvel, proposto no Questionário 1 (detalhes sobre esse problema podem ser consultados em Heidemann, 2015). Já no final da disciplina, a estudante, que utilizou o modelo de movimento retilíneo uniformemente variado na resolução do problema, afirmou ter considerado que "a estrada não possuía buracos", o que é uma simplificação coerente com o modelo utilizado. No entanto, ela não destacou qualquer simplificação referente à aceleração do automóvel, que precisa ser considerada constante para utilizar o modelo explorado no problema. 
As dificuldades dos estudantes 1, 2, 4 e 5 de simplificar eventos reais durante o processo de modelagem foram bastante evidentes quando, no questionário respondido ao final da disciplina, era solicitado que apresentassem as simplificações da realidade que precisariam ser consideradas na análise dos dados experimentais da posição em função do tempo de um móvel que desliza em um trilho de ar. Os dados da posição contra o tempo mostravam que móvel se movimenta com velocidade aproximadamente constante. No entanto, os quatro estudantes citados propuseram o uso do modelo de movimento retilíneo uniformemente variado para resolver o problema, quando seria mais adequado considerá-lo um movimento uniforme. Desse modo, os estudantes evidenciam não ter desenvolvido esquemas de ação adequados para enfrentar situações em que precisam decidir quais dos seus traços-chave apreender quando constroem um modelo teórico.

O estabelecimento de um vínculo entre as simplificações da realidade consideradas no modelo teórico de referência de suas investigações e o delineamento de seus experimentos é um aspecto em que os estudantes 1, 3, 4 e 5 tiveram dificuldades. Por exemplo, ainda que tenha mencionado as idealizações consideradas nos seus modelos em três dos seus quatro relatórios, a Estudante 5 não relacionou essas simplificações com procedimentos de controle de variáveis dos seus experimentos nem mesmo com as deduções matemáticas presentes em seus relatórios. A falta de vínculo entre modelo e experimento nas investigações se mostrou presente também na resposta da estudante em uma questão do Questionário $1 \mathrm{em}$ que é questionado se seria necessário considerar alguma simplificação da realidade na análise dos dados coletados em um experimento proposto por ela para investigar os fatores que influenciam na intensidade da força resistiva do ar sobre corpos que se movem em relação a ele (essa questão por ser consultada em Heidemann, 2015). A resposta da Estudante 5 foi:

Acho que não, pois o objetivo seria avaliar o comportamento da força resistiva do ar em situações com objetos diferentes e, geralmente, é ela que desprezamos. Qualquer "imperfeição" (rugosidades, formatos irregulares) dos objetos também seria importante não desprezar (ou idealizar que não existem), pois são fatores relevantes para o experimento.

A estudante demonstra acreditar que pode construir uma representação de um experimento em que considera a realidade em sua totalidade. Os estudantes 2 e 4 apresentaram respostas semelhantes à da Estudante 5.

Provavelmente em função da dificuldade de relacionar simplificações da realidade e o controle de variáveis, os estudantes 1, 3, 4 e 5, quando solicitados a expor os fatores que explicavam as diferenças entre os dados experimentais e as predições dos modelos teóricos, propunham somente fatores relacionadas com a imprecisão dos instrumentos de medida utilizados, desprezando influências oriundas de problemas relacionados com a falta de controle sobre fatores desprezados nos modelos de referência dos experimentos que efetivamente influenciam em seus resultados. A Estudante 1, por exemplo, no relatório da atividade "Arquimedes e a Coroa do Rei", justifica as diferenças identificadas entre duas medidas realizadas por meio de métodos distintos dizendo: "A diferença observada pode ser devido à calibragem das balanças, ou a equívocos no momento da leitura dos dados". Nesse caso, a estudante não destaca que as simplificações da realidade consideradas no modelo teórico de referência do seu experimento influencia nas medidas realizadas. Desse modo, demonstra não ter 
construído esquemas de ação adequados para enfrentar situações que demandam a avaliação qualitativa e/ou quantitativamente da incerteza introduzida pelas simplificações da realidade consideradas nas predições de um modelo teórico.

A construção de conclusões nas investigações com base nas evidências coletadas é outra dificuldade enfrentada pelas estudantes 1 e 5 nas atividades de modelagem. No relatório da atividade "Sistema de Amortecimento Automotivo", por exemplo, a Estudante 5 afirmou: "Os dados obtidos não estão muito longe do esperado a partir do modelo teórico. [...] Apesar disso há uma certa incoerência nos valores de $b$ [constante de amortecimento do sistema] para o álcool e o detergente, quando os comparamos. Nos dois líquidos o tempo de oscilação foi aproximadamente o mesmo mas seus valores de b são bem distintos". Nessa passagem, pode-se perceber que a estudante valida o modelo teórico utilizado apesar da importante incoerência que ela detectou entre as predições do seu modelo teórico de referência e os dados coletados empiricamente. Demonstra-se assim que a estudante, ainda que argumente que procura avaliar a adequação dos modelos para representar eventos reais, internamente parte do pressuposto de que o seu modelo teórico de referência é válido na sua investigação. Esse dado vai ao encontro dos achados de Marineli e Pacca (2014), que identificam estudantes que, em atividades experimentais, "afirmam que os resultados concordam com o esperado ou que 'deu certo' mesmo que os dados mostrem o contrário". Esses estudantes demonstram não ter construído invariantes operatórios para enfrentar situações em que precisam analisar a razoabilidade das predições dos modelos científicos por meio da busca de suportes empíricos e/ou racionais.

A análise de dados demonstra que as atividades experimentais foram frutíferas para defrontar os estudantes com situações que envolvem conceitos e esquemas de ação relacionados com o campo conceitual da modelagem didáticocientífica, porém os avanços dos estudantes em suas competências para enfrentar situações de modelagem foram bastante tímidos. Desse modo, em função das grandes dificuldades demonstradas pelos estudantes para enfrentar situações de modelagem mesmo ao final da disciplina, podemos dizer que a proposição teórica testada não foi corroborada pelos dados coletados, pois foram muito restritos os conhecimentos desenvolvidos pelos estudantes relacionados com o campo conceitual da modelagem didático-científica. Por outro lado, podemos dizer também que as atividades efetivamente defrontaram os estudantes com situações de modelagem. Como foi mencionado na exposição das proposições teóricas, julgávamos que essas características das atividades justificavam nossa expectativa de que os alunos construiriam esquemas de ação adequados para enfrentar situações de modelagem, o que, de fato, não ocorreu de forma satisfatória.

\section{CONSIDERAÇÕES FINAIS}

As atividades de modelagem tiveram o mérito de proporcionar debates entre os alunos sobre conceitos importantes dentro do campo conceitual da modelagem didático-científica. No entanto, os resultados mostraram que os avanços dos estudantes, tanto em relação às suas concepções sobre esses conceitos como em relação às suas competências para enfrentarem situações de 
modelagem, foram bastante limitados. Cabe ressaltar, no entanto, que o estudo foi realizado com uma turma pequena que continha alguns alunos peculiares. $O$ Estudante 2 não esteve ativamente envolvido nas atividades em função da sua atitude bastante negativa em relação às aulas de laboratório e de ele estar se dedicando com mais afinco ao desenvolvimento do seu trabalho de mestrado em Química do que ao seu curso de graduação em Física. A Estudante 3 apresentava um histórico de muitas reprovações nas disciplinas anteriormente cursadas, sendo muitas delas por falta de frequência, inclusive na mesma disciplina na qual o estudo foi realizado. Já o Estudante 4 não se alinhou com a proposta de desenvolvimento de atividades abertas realizada na disciplina, e, além disso, também apresentava um histórico de reprovações. Desse modo, concluímos que a turma investigada não constituía um caso típico, contrariando a expectativa que tínhamos quando delineamos o estudo. Por isso, é prudente que os resultados obtidos sejam avaliados de forma crítica, considerando que o caso estudado acabou por não ser muito representativo do universo dos alunos que costumam se matricular na disciplina investigada.

Ainda que o caso investigado tenha se mostrado peculiar, pudemos constatar que todos os estudantes apresentaram significativas dificuldades para relacionarem os modelos teóricos utilizados em suas investigações com o trabalho experimental. As evidências sugerem que eles não costumavam relacionar o conceito de modelagem com o processo de validação dos modelos teóricos. Tratando-se de uma disciplina experimental em que a promoção da contrastação empírica de modelos teóricos é um dos seus principais enfoques, é fundamental que os estudantes relacionem o processo de modelagem com o trabalho experimental. Em função disso e dos resultados deste estudo, concluímos que era necessário um aprofundamento teórico da concepção do campo conceitual da modelagem didático-científica de Brandão, Araujo e Veit (2011) com vistas a esclarecer como os processos relacionados com o trabalho experimental se vinculam dentro desse campo conceitual. Esse aprofundamento teórico já foi realizado e é apresentado em Heidemann (2015) e em Heidemann, Araujo e Veit (2015b).

É importante apresentar aqui também uma reflexão sobre as vantagens do desenvolvimento de discussões finais nas atividades de modelagem. Dois aspectos se destacam nas discussões conduzidas neste estudo. São eles:

i) A capacidade dos estudantes de se expressarem de forma verbal é uma competência que precisa ser desenvolvida pelos alunos, e as discussões finais contribuíram para que progredissem nessa competência. A Estudante 3, por exemplo, teve grandes dificuldades para se expressar na primeira discussão final. Ela não conseguiu explicitar aos colegas o que desejava em função da vergonha que sentia, terminando sua fala afirmando que "deu um branco". Em entrevista, ela destacou que não se sentia confortável se expressando ao grande grupo. No entanto, na última atividade de modelagem, ela foi a estudante que mais participou do debate, evidenciando ter evoluído em suas habilidades para se expressar.

ii) As discussões finais suscitaram debates que provavelmente não teriam ocorrido espontaneamente entre os alunos em uma aula tradicional. Abaixo, são apresentados dois deles (mais exemplos são relatados em Heidemann, 2015): 
a) "Ligar" ou não os pontos em um gráfico: Na primeira atividade de modelagem, um grupo de estudantes representou seus dados coletados experimentalmente por meio de um gráfico em que os estudante "ligaram" os pontos experimentais por linhas contínuas. Tal ocasião suscitou um debate com a professora sobre a interpretação de dados representados em gráficos, destacando-se que não é desejável que os pontos experimentais sejam conectados.

b) Relação entre densidades de corpos: Na atividade "Arquimedes e a Coroa do Rei", um grupo de estudantes utilizou a relação $\rho_{t}=\alpha \cdot \rho_{A l}+b . \rho_{P b}$, onde $\rho_{t}$ é a densidade total de um corpo formado apenas por Alumínio e Chumbo, $\rho_{A l}$ é a densidade do Alumínio, $\rho_{P b}$ é a densidade do Chumbo, e $\alpha$ e $b$ são as proporções dos dois componentes na amostra. Um questionamento da professora suscitou uma discussão sobre a validade da equação: ela é válida quando as proporções $\alpha$ e $b$ envolvem razões sobre a massa ou sobre o volume da amostra? Por meio da discussão final, os alunos concluíram que ela é válida quando as razões $\alpha$ e $b$ se referem a proporções dos volumes dos componentes.

Em relação às proposições teóricas testadas no estudo, podemos dizer que são necessárias mais evidências em outros contextos para que possamos construir uma conclusão mais sólida sobre o pressuposto que tínhamos no início da investigação de que as atividades de modelagem promoveriam atitudes mais positivas dos estudantes em relação às atividades de laboratório. Pode-se constatar que a liberdade conferida aos estudantes para tomarem decisões sobre as características das suas investigações foi considerada excessiva por dois dos participantes, pois eles se sentiram desnorteados especialmente no princípio das atividades. Constatou-se também que três estudantes construíram atitudes positivas em relação às atividades de modelagem, ressaltando que essas atividades enfatizam as relações dos experimentos de laboratório com os eventos físicos que eles buscam reproduzir, dando sentido aos conteúdos científicos. Destaca-se que os três estudantes que construíram atitudes positivas frente às atividades conduzidas eram do sexo feminino, o que vai ao encontro dos resultados de Brewe et al. (2009). Esses autores observaram que atividades com enfoque no processo de modelagem científica promovem a integração de estudantes pertencentes a algumas minorias como hispânicos, mulheres e negros.

As dificuldades enfrentadas pelos estudantes decorrentes da liberdade que Ihes foi concedida durante as atividades demonstram que a transição de atividades experimentais fechadas, baseadas em roteiros fortemente dirigidos, para atividades abertas, baseadas em autênticos problemas, não pode ser realizada de forma abrupta. Tal conclusão é compreensível, pois, assim como o que ocorre em qualquer campo conceitual, o progresso dos estudantes sobre o domínio do campo conceitual da modelagem é lento e penoso, envolvendo avanços e retrocessos que ocorrem na medida em que os estudantes enfrentam novas situações. Desse modo, para que os alunos não se sintam desorientados nas atividades, as situações de modelagem propostas a eles precisam ter um aumento gradual de complexidade condizente com os seus avanços no domínio do campo conceitual da modelagem didático-científica.

Avaliando-se as proposições teóricas construídas para a segunda questão de pesquisa do estudo, podemos dizer que as atividades efetivamente defrontaram os estudantes com situações do campo conceitual da modelagem didático- 
científica, oportunizando momentos que demandavam que eles desenvolvessem conhecimentos relacionados com o processo de modelagem científica para resolverem os problemas propostos. No entanto, o avanço dos estudantes relacionado com seus domínios do campo conceitual da modelagem didáticocientífica foram aquém do esperado.

O compartilhamento na forma verbal dos objetivos de aprendizagem das atividades e os debates explícitos sobre metamodelagem promovidos não foram suficientes para possibilitar que os estudantes construíssem significados adequados para três dos principais conceitos do campo conceitual da modelagem didático-científica, especificamente os conceitos de modelo, teoria e modelagem científica, e também possibilitaram que eles evoluíssem apenas de forma muito acanhada em suas capacidades para enfrentarem autênticos problemas, em que precisassem tomar decisões sobre os modelos científicos a serem utilizados para resolvê-los. Nossos resultados corroboram os estudos de Guillon e Séré (2002) que, propondo problemas experimentais abertos para estudantes de graduação em Física, observaram que eles, além de apresentarem grandes dificuldades para enfrentá-los, não conseguem narrar o que fazem nas investigações relacionandoas com os debates sobre modelagem realizados pelos pesquisadores. 


\title{
An explanatory case study about the development of experimental activities focused on the process of scientific modeling for physics education
}

\begin{abstract}
Experimental activities conducted in undergraduate physics courses usually stimulate students to act mechanically, not requiring them to think about the theoretical framework their investigations are based upon. This kind of activity contribute toward a dichotomized learning, in which theoretical and experimental aspects are treated in a dissociate manner. Concerned with this scenario, the purpose of the present explanatory study is to evaluate the potential of experimental activities planned to promote the association of theory and practice on physics education through scientific modeling. The planning of the modeling activities about mechanical oscillations, fluids and thermodynamics phenomena, as well as the data analysis, was based on the theoretical- methodological framework of Brandão, Araujo and Veit. It was evaluated the influence of the experimental activities conducted on: the attitudes of undergraduate physics majors toward laboratory class; their understanding about concepts related to the process of scientific modeling; and their advancement and difficulties to face situations related to the construction, application and validation of didactic-scientific models. The results shown: i) the freedom the student had to design and conduct their experiments was a determining factor for them to build favorable or unfavorable attitudes toward experimental activities; ii) the students remained confuse regarding the concepts of model, theory and modeling; iii) the advancement on their competence to face the proposed situations was rather timid.
\end{abstract}

KEYWORDS: experimental physics activities. scientific modeling. didactic-scientific modeling. 


\section{REFERÊNCIAS}

Brandão, R. V.; Araujo, I. S. e E. A. Veit (2011). A modelagem científica vista como um campo conceitual. Caderno Brasileiro de Ensino de Física, 28, 3, 507-545.

Brandão, R. V.; Araujo, I. S. e E. A. Veit (2012). Scientific modeling seen as a conceptual field: theoretical approach and preliminary empirical evidences of possible operational invariants on the learning of physics. In: The World Conference on Physics Education - Book of Abstracts. (pp. 273-282). Istambul: Bahesehir Universitesi.

Brewe, E.; Sawtelle, V.; Kramer, L.; O’brien, G.; Rodriguez, I. e P. Pamelá (2010). Toward equity through participation in Modeling Instruction in introductory university physics. Physical Review Special Topics - Physics Education Research, 6, 1, $01010612 \mathrm{pp}$.

Bunge, M. (1974) Teoria e realidade. São Paulo: Editora Perspectiva.

Field, A. (2009). Discovering statistics using SPSS (and sex and drugs and rock ' $n$ ' roll). Dubai: SAGE Publications.

Justi, R. y J. K. Gilbert (2002). Modelling, teachers' view on the nature of modelling, and implications for the education of modellers. International Journal of Science Education, 24, 4, 369-87.

Heidemann, L. A. (2015). Ressignificação da atividades experimentais no ensino de Física por meio do enfoque no processo de modelagem científica. 2015. 298 f. Tese (Doutorado em Ensino de Física) - Instituto de Física, Universidade Federal do Rio Grande do Sul, Porto Alegre.

Heidemann, L. A.; Araujo, I. S. e E. A. Veit (2012a). Um referencial teóricometodológico para o desenvolvimento de pesquisas sobre atitude: a Teoria do Comportamento Planejado de Icek Ajzen. Revista Electrónica de Investigación en Educación en Ciencias, 7, 1, 1-10. 
Heidemann, L. A.; Araujo, I. S. e E. A. Veit (2012b). Ciclos de Modelagem: uma alternativa para integrar atividades baseadas em simulações computacionais e atividades experimentais no ensino de Física. Caderno Brasileiro de Ensino de Física, 29, Especial 2, 965-1007.

Heidemann, L. A.; Araujo, I. S.; Veit, E. A. e F. L. Silveira (2013). Um Ciclo de Modelagem sobre a Lei de Resfriamento de Newton. In: XX Simpósio Nacional De Ensino De Física. São Paulo: Sociedade Brasileira de Física.

Heidemann, L. A.; Araujo, I. S. e E. A. Veit (2014). Apresentações de slides utilizadas nas atividades de modelagem. Em: http://www.if.ufrgs.br/gpef/modelagem/Fis_II_A_2013/.

Heidemann, L. A.; Araujo, I. S. e E. A. Veit (2015a). A integração de atividades teóricas e experimentais no Ensino de Física através de ciclos de modelagem: um estudo de caso exploratório no Ensino Superior. Submetido a Revista Alexandria.

Heidemann, L. A.; Araujo, I. S. e E. A. Veit (2015b). Teoria da Modelagem Didático-Científica: integrando atividades experimentais e o processo de modelagem científica no ensino de Física. Submetido ao Caderno Brasileiro de Ensino de Física.

Hestenes, D. (2006). Notes for a Modeling Theory of Science, Cognition and Instruction. In: Proceedings of GIREP Conference: Modelling In Physics And Physics Education. Amsterdam: University of Amsterdam.

Hodson, D. (1994). Hacia un enfoque más crítico del trabajo de laboratorio. Enseñanza de las Ciencias, 12, 3, 299-313.

Marineli, F. e J. L. A. Pacca (2014). Dificuldades de estudantes em um laboratório didático: uma interpretação baseada em conceituações sobre a realidade. Revista Electrónica de Investigación en Educación en Ciencias, 9, 2, 13-27.

Otero, M. R. (2006). Emociones, sentimientos y razonamientos en didáctica de las Ciencias. Revista Electrónica de Investigación en Educación en Ciencias, 1, 1, 2453.

Trumper, R. (2003). The physics laboratory - A historical overview and future perspectives. Science \& Education, 12, 7, 645-670. 
Vergnaud, G. (1993). Teoria dos campos conceituais. In: 1o Seminário Internacional de Educação Matemática do Rio de Janeiro. Rio de Janeiro: IMUFRJ.

Vergnaud, G. (2009). The theory of conceptual fields. Human Development, 52, 2, 83-94.

Yin, R. K. (2005). Estudo de caso: planejamento e métodos. Porto Alegre: Bookman.

Yin, R. K. (2011). Qualitative research from start to finish. New York: The Guilford Press.

Recebido: 2017-03-12

Aprovado: 2017-05-24

DOI: $10.3895 /$ rbect.v10n3.5672

Como citar:

HEIDEMANN, L. A.; ARAUJO, I. S.; VEIT, E. A.. Um estudo de caso explanatório sobre o desenvolvimento de atividades experimentais com enfoque no processo de modelagem científica para o ensino de Física. Revista

Brasileira de Ensino de Ciência e Tecnologia, v. 10, n. 3, 2017. Disponível em:

$<$ https://periodicos.utfpr.edu.br/rbect/article/view/5672>. Acesso em: XXXXXXX.

Correspondência: Leonardo Albuquerque Heidemann - leonardo.h@ufrgs.br

Direito autoral: Este artigo está licenciado sob os termos da Licença Creative Commons-Atribuição 4.0

Internacional.

(c) (i) 